\title{
Prevalence of cerebral microbleeds and other cardiovascular risk factors in elderly patients with acute ischemic stroke
}

\author{
Abeer Abdelzaher Ibrahim', Yosra Abdelzaher Ibrahim² ${ }^{2}$, Eman A. Darwish² and Nivan Hany Khater ${ }^{2}$
}

\begin{abstract}
Background: Cerebral microbleeds are small, round dark-signal foci in the $\mathrm{T2}^{*}$-weighted magnetic resonance imaging. They are encountered in cerebral amyloid angiopathy and hypertensive vasculopathy. Their prevalence is common in ischemic stroke and cerebral hemorrhage. The purpose of this study is to investigate the prevalence of CMBs and associated risk factors in the elderly patients with acute ischemic stroke.

Results: Cerebral microbleeds were significantly associated with the presence of hypertension (in the subgroup of recurrent stroke) and with hypercholesterolemia. There was a significant association between the number of the microbleeds and severity of white matter lesions as a higher number of microbleeds related to more severe white matter lesions. The microbleeds were more prevalent in the group of patients using antithrombotics.

Conclusion: Age, hypercholesterolemia, and the use of antithrombotics emerged as the most important associated risk factors for the presence of $\mathrm{CMBs}$. On MRI, there was a significant association between the number of CMBs and severity of white matter lesions as a higher number of $\mathrm{CMBs}$ related to more severe white matter lesions.
\end{abstract}

Keywords: Cerebral microbleeds, T2*WI, Ischemic stroke, Elderly

\section{Background}

Cerebral microbleeds (CMB) were defined as small round dark-signal lesions encountered by $\mathrm{T} 2$ "'-weighted or gradient-echo (GRE) magnetic resonance imaging (MRI) [1]. These were presented to the clinical practice in the late 1990s and early 2000s after the evolution of MRI techniques sensitive to paramagnetic effects [2]. Histologically, they are tiny foci containing hemosiderin-laden macrophages in close spatial relation with abnormal blood vessels [3].

Two main types of vasculopathies have been linked with $\mathrm{CMBs}$ in the aging brain: cerebral amyloid angiopathy (CAA) and hypertensive vasculopathy (HV). CAA occurs as a result of the accumulation of $\beta$-amyloid on the vessel walls of cortical and leptomeningeal arteries, whereas HV is associated with long-standing hypertension and appears as lipofibrohyalinosis of the deep penetrating arterioles. Since both forms are associated with age, they may

\footnotetext{
*Correspondence: yosra_ibrahim@med.asu.edu.eg; yosra_zaher@yahoo.com ${ }^{2}$ Radiology Department, Faculty of Medicine, Ain Shams University, Abbaseya Square, Cairo 11566, Egypt

Full list of author information is available at the end of the article
}

co-occur in a single person with different degrees of severity [4].

The clinical significance of CMBs has mainly been demonstrated in the light of cerebral hemorrhage and ischemic stroke, as their prevalence is common in both conditions [5]. They are considered as a marker of future stroke risk [6]. In addition, they have an independent association with cognitive dysfunction [7].

The reported prevalence of CMBs in ischemic stroke patients differs considerably $\{35-71 \%\}[8-13]$. This may be attributed to the heterogeneity of ischemic stroke per se or to differences in studied populations. Ethnicity may play a role in the prevalence of CMB.

The purpose of this study is to investigate the prevalence of CMBs and associated risk factors in the elderly patients with acute ischemic stroke.

\section{Methods \\ Patients}

The study was approved by the local institutional review board. 
A retrospective study of elderly patients presented with acute ischemic stroke (primary or recurrent), in the period between January 2017 and December 2018, was conducted in Ain Shams University Hospitals which is one of the biggest tertiary hospitals in Cairo. The collected patient's data included the following:
- Age and sex

- History of vascular risk factors including hypertension, diabetes mellitus, atrial fibrillation, hypercholesterolemia, and smoking

- History of antithrombotic treatment (antiplatelets or anticoagulants)
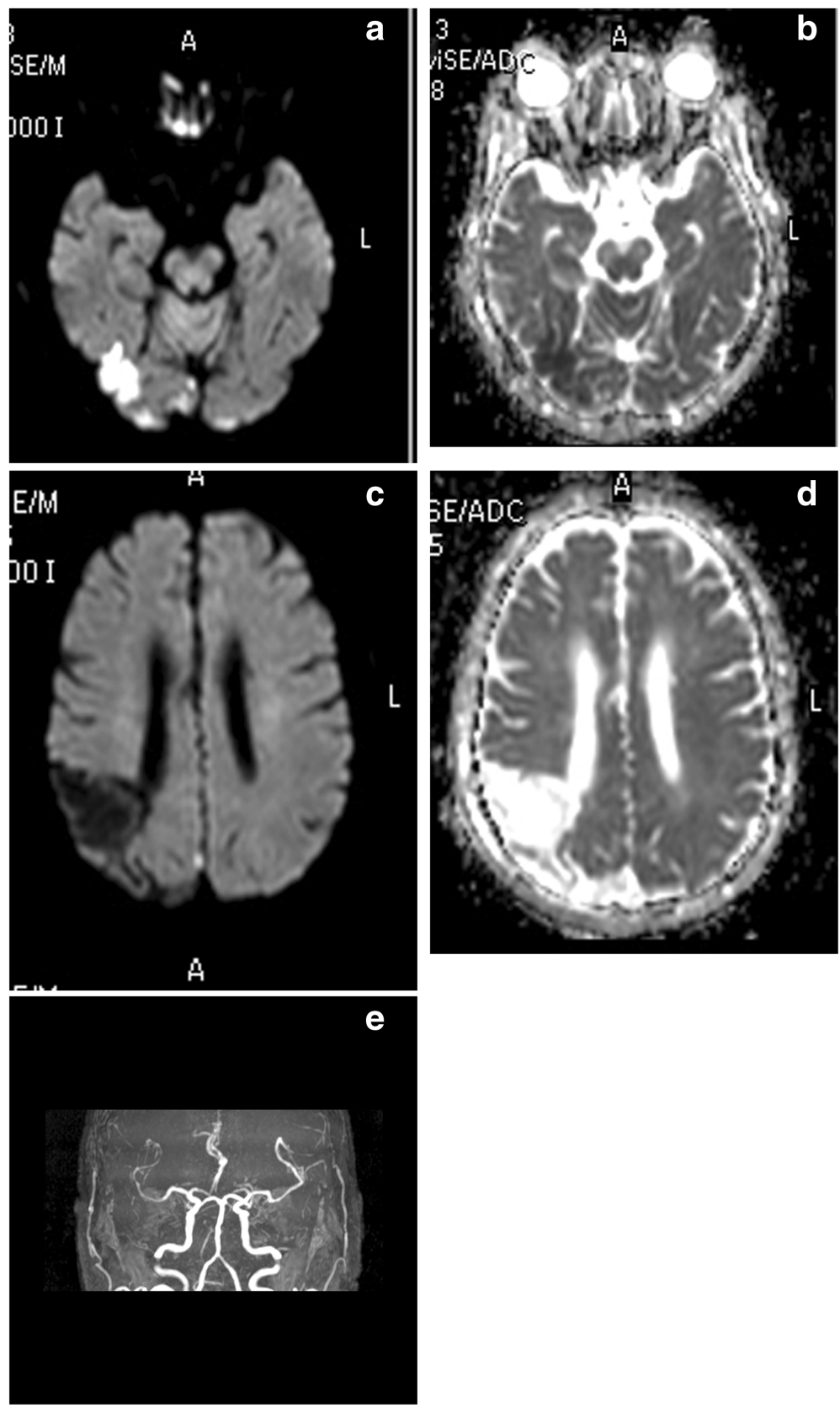

Fig. 1 Recurrent atherothrombotic stroke in a 70-year-old male. There is a recent right occipital infarction evident by restricted diffusion in the DWI (b $=1000 \mathrm{~s} / \mathrm{mm}^{2}$ ) (a) with corresponding low signal on the ADC map (b). Higher cuts reveal an old right posterior parietal infarction showing dark signal on the DWI (c) with high signal on the ADC map (d) denoting facilitated diffusion. Time of flight cerebral MRA (maximum intensity projection-MIP) (e) shows diffuse atherosclerotic changes of the cerebral arteries expressed by vessels beading, attenuation, and reduced peripheral branching 
- Brain MRI and cerebral MRA (magnetic resonance angiography) findings

Ischemic stroke was classified according to the criteria of the National Institute of Neurologic Disorders and Stroke [14] as atherothrombotic infarction, cardio-embolic infarction, and lacunar infarction.

Inclusion criteria:

- Age $\geq 60$ years

- No sex predilection

- Acute ischemic stroke presentation

Exclusion criteria:

- Age less than 60 years

- Cases of undetermined stroke subtype

- Patients with no or poor quality MR images

\section{MR imaging sequences and interpretation}

Brain MRI examinations were performed on a superconducting 1.5 T unit (Achieva; Philips Medical Systems, Best, the Netherlands).

All patients were scanned using standard stroke protocol with a dedicated head coil. The pulse sequences included:

- Axial T1-weighted (T1W) images (fast spin-echo sequence): repetition time $(\mathrm{TR})=597 \mathrm{~ms}$, echo time $(\mathrm{TE})=15 \mathrm{~ms}$, number of excitations (NEX) 2, flip angle 90, matrix $137 \times 208$ with a field of view (FOV) $230($ AP) $\times 186(\mathrm{RL}) \times 131(\mathrm{FH}) \mathrm{mm}$, slice thickness $5 \mathrm{~mm}$, and gap $0 \mathrm{~mm}$.

- Axial T2-weighted (T2W) images (fast spin-echo sequence): $\mathrm{TR}=4845 \mathrm{~ms}$, TE $=110 \mathrm{~ms}$, NEX 2, flip angle 90, matrix $147 \times 256$ with FOV 230 (AP) $\times$ $183(\mathrm{RL}) \times 131(\mathrm{FH}) \mathrm{mm}$, slice thickness $5 \mathrm{~mm}$, and gap $0 \mathrm{~mm}$.

- Axial FLAIR (fluid-attenuated inversion recovery) images: TI (inversion time) $=2800 \mathrm{~ms}, \mathrm{TR}=11000$ $\mathrm{ms}, \mathrm{TE}=130 \mathrm{~ms}$, NEX 2, flip angle 90, matrix $137 \times$ 208 with FOV $230(\mathrm{AP}) \times 184(\mathrm{RL}) \times 131(\mathrm{FH}) \mathrm{mm}$, slice thickness $5 \mathrm{~mm}$, and gap $0 \mathrm{~mm}$.

- Axial diffusion-weighted (DW) images: $\mathrm{TR}=3724$ $\mathrm{ms}, \mathrm{TE}=117 \mathrm{~ms}, b$ value $=0$ and $1000 \mathrm{~s} / \mathrm{mm}^{2}$, matrix $105 \times 136$ with FOV $232(\mathrm{AP}) \times 202(\mathrm{RL}) \times$ $131(\mathrm{FH}) \mathrm{mm}$, slice thickness $5 \mathrm{~mm}$, and gap $0 \mathrm{~mm}$.

- Axial T2*-weighted (T2*W) images: TR $=691 \mathrm{~ms}$, $\mathrm{TE}=23$ ms, matrix $133 \times 208$ with FOV $230(\mathrm{AP}) \times$ 184 $(\mathrm{RL}) \times 131(\mathrm{FH}) \mathrm{mm}$, slice thickness $5 \mathrm{~mm}$, and gap $0 \mathrm{~mm}$.

- Time of flight MRA of the circle of Willis.

The MR images were analyzed by 3 neuro-radiologists who were blinded to the old radiological reports.

Acute ischemic stroke was evident on the DWI as an area of diffusion restriction with corresponding low signal on the ADC map (Fig. 1).

Old strokes were depicted as gliotic/malacetic areas showing bright T2WI signal and low T1WI+/- FLAIR

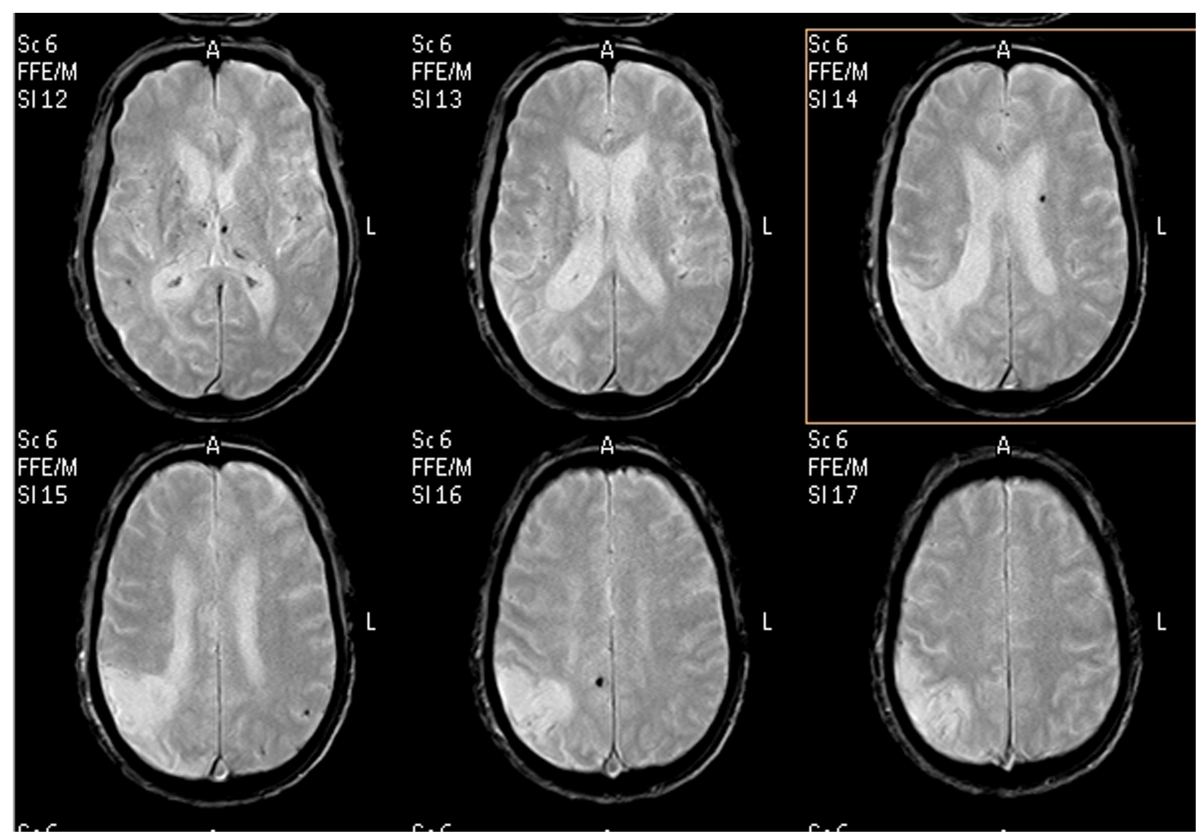

Fig. 2 Sequential cuts of T2*WI showing several dark signal foci of blooming scattered in both hemispheres representing grade 2 microbleeds 
Table 1 Grading of cerebral micro-bleeds

\begin{tabular}{ll}
\hline Grade & Number of microbleeds \\
\hline 0 & 0 \\
1 (mild) & $1-2$ \\
2 (moderate) & $3-10$ \\
3 (severe) & $>10$ \\
\hline
\end{tabular}

signal with no diffusion restriction and high signal on the ADC map (Fig. 1). Patients with old strokes were sub-grouped as recurrent strokes.

T2 GRE images were analyzed for the presence or absence of cerebral micro-bleeds. The grading scale of Lee et al. [15] was used [Fig. 2] which is summarized in Table 1.

White matter FLAIR hyperintensities (leukoaraiosis) were graded using the scoring system prescribed by Fazekas et al. [16] as grade 0, absent; grade 1, punctate white matter foci; grade 2, early confluent lesions; and grade 3, confluent lesions (Fig. 3).

Baseline characteristics, stroke subtypes, and severity of white matter lesions were compared between patients with and without CMBs.

\section{Statistical methods}

IBM SPSS statistics (V. 25.0, IBM Corp., USA, 2017-2018) was used for data analysis. The date was expressed as mean \pm SD for quantitative parametric measures in addition to both number and percentage for categorized data.

The following tests were done:

1. Comparison between two independent mean groups for parametric data using Student $t$ test.

2. Chi-square test to study the association between each 2 variables or comparison between 2 independent groups as regards the categorized data.
3. One-way ANOVA test (\#post hoc test)

The probability of error at $<0.05$ was considered statistically significant

\section{Results}

A total of 374 elderly patients (198 males and 176 females) with acute ischemic stroke were included in the study. Their age ranged from 60 to 93 years (mean age $68, \pm 6.772 \mathrm{SD}) .52 .9 \%$ were males and $47.1 \%$ were females. Among the cardiovascular risk factors, dyslipidemia had the highest prevalence $(65.85 \%)$ in the studied patients.

Table 2 shows the baseline characteristics of the study population.

The prevalence of CMBs among all the participants was found to be $29.4 \%$ (110/374 patients).

As shown in Table 3, the grade of microbleeds is significantly associated with older age $(P=0.03)$.

CMBs were also significantly associated with the presence of hypertension in the subgroup of recurrent stroke $(P=0.04)$ but not in patients with primary stroke $(P=$ 0.17 ), as described in Tables 4 and 5 .

In our study population, CMBs showed significant association with hypercholesterolemia $(P<0.001)$ (Table 6).

There was no significant association between the presence of microbleeds and stroke subtypes nor recurrent stroke (Table 7).

CMBs were found to occur more frequently in deep brain areas in hypertensive patients $(P<0.001)$ as demonstrated in Table 8 .

There was a significant association between the number of CMBs and severity of white matter lesions as a higher number of CMBs related to more severe white matter lesions $(P<0.001)$, as shown in Table 9 .

The microbleeds were more prevalent in the group of patients using antithrombotics $(P<0.001)$ (Table 10).
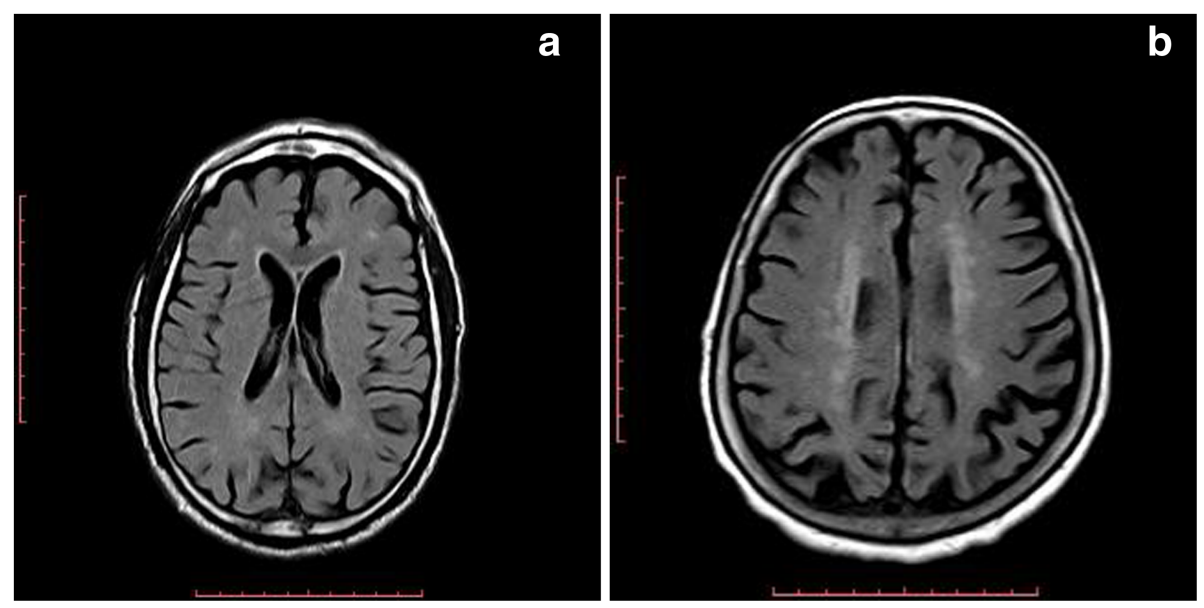

Fig. 3 Axial FLAIR in two different patients showing grade 1 (a) and grade 3 (b) white matter hyperintensities according to Fazeka's grading 
Table 2 Baseline characteristics of the study population

\begin{tabular}{|c|c|}
\hline Baseline characteristic & $\begin{array}{l}\text { Number of patients } \\
(n=374), n(\%)\end{array}$ \\
\hline \multicolumn{2}{|l|}{ Sex } \\
\hline Male & $198(52.9 \%)$ \\
\hline Female & $176(47.1 \%)$ \\
\hline Mean age(range, years) & $68(60-93)$ \\
\hline Hypertension & $230(61.5 \%)$ \\
\hline Diabetes mellitus & $188(50.3 \%)$ \\
\hline Hyperlipidemia & $264(65.8 \%)$ \\
\hline Atrial fibrillation & $30(8 \%)$ \\
\hline Smoking & $80(21.3 \%)$ \\
\hline Old stroke & $212(56.7 \%)$ \\
\hline \multicolumn{2}{|l|}{ Stroke subtypes } \\
\hline Atherothrombotic infarction & $236(63.3 \%)$ \\
\hline Cardioembolic infarction & $22(5.8 \%)$ \\
\hline Lacunar infarction & $116(31 \%)$ \\
\hline \multicolumn{2}{|l|}{ CMBs } \\
\hline Absent & $110(29.4 \%)$ \\
\hline Grade 1 & $264(70.6 \%)$ \\
\hline Grade 2 & 78 (20.9\%) \\
\hline Grade 3 & $16(4.3 \%)$ \\
\hline \multicolumn{2}{|l|}{ Location of microbleeds } \\
\hline Cortico-subcortical region & $58(51.8 \%)$ \\
\hline Deep and infratentorial region & $40(35.7 \%)$ \\
\hline Cortico-subcortical and deep & $14(12.5 \%)$ \\
\hline \multicolumn{2}{|l|}{ Fazekas score } \\
\hline 0 & $54(14.4 \%)$ \\
\hline 1 & 116 (31\%) \\
\hline 2 & $132(35.3 \%)$ \\
\hline 3 & $72(19.3 \%)$ \\
\hline Antithrombotic use & $112(29.9 \%)$ \\
\hline Antiplatelets & 88 \\
\hline Anticoagulant & 24 \\
\hline
\end{tabular}

Table 3 Relation between age and grade of microbleeds

\begin{tabular}{llllll}
\hline & & Age & $F^{\text {a }}$ & $P$ \\
\cline { 3 - 4 } & & Mean & SD & & value \\
\hline Microbleeds grade & 1.00 & 68.18 & 6.06 & 3.87 & 0.03 \\
& 2.00 & $72.25^{\mathrm{b}}$ & 8.58 & & \\
& 3.00 & $63.62^{\mathrm{b}}$ & 3.70 & & \\
\hline
\end{tabular}

One-way ANOVA test ( ${ }^{\mathrm{b}}$ post hoc test)
Table 4 Relation between hypertension and the presence of microbleeds in patients with primary stroke

\begin{tabular}{|c|c|c|c|c|c|c|c|}
\hline & & \multicolumn{4}{|c|}{ Microbleeds } & \multirow{3}{*}{$\begin{array}{l}\text { Chi- } \\
\text { square } \\
\text { test }\end{array}$} & \multirow{3}{*}{$\begin{array}{l}P \\
\text { value }\end{array}$} \\
\hline & & \multicolumn{2}{|c|}{ Positive } & \multicolumn{2}{|c|}{ Negative } & & \\
\hline & & $\bar{N}$ & $\%$ & $\bar{N}$ & $\%$ & & \\
\hline \multirow[t]{2}{*}{ Hypertension } & Negative & 20 & 50.0 & 40 & 32.8 & 1.91 & 0.17 \\
\hline & Positive & 20 & 50.0 & 82 & 67.2 & & \\
\hline
\end{tabular}

\section{Discussion}

With the widespread of MRI in stroke patients, CMBs have been commonly encountered which emphasized considerable prevalence and significance of CMBs in the aging population [17]. As the prevalence of CMBs varies tremendously depending on the MRI study characteristics and the selection of the study population, the reported prevalence in different clinical conditions has greatly broad ranges: 47 to $80 \%$ in intracranial hemorrhage $[10,18], 18$ to $71 \%[9,19]$ in ischemic stroke, or 17 to $46 \%$ in cognitive decline/dementia [20]. On the other hand, several population-based studies have also reported $\mathrm{CMB}$ prevalence in subjects without a history of cerebrovascular disease to be between 3 and $7 \%$ [21-23].

In the present study, the prevalence of CMBs was found to be $29.4 \%$ in the Egyptian elderly with acute ischemic stroke which is lower than reported by Koennecke HC [5] (40\%) but close to a report from a Chinese study that found prevalence of CMBs to be $24 \%$ in Chinese patients with ischemic stroke [24].

Several studies reported that the prevalence of CMBs increased with age in adult participants without stroke $[5,23]$. In our study, we found that the grade of microbleeds is significantly associated with older age.

In our study population, $61.5 \%$ were hypertensive. Despite this, we did not find a significant association of hypertension with CMBs except in the subgroup of recurrent stroke.

In several studies, hypertension has not steadily been found to be associated with microbleeds. Jeerakathil et al. [8] found an association between microbleeds and hypertension which disappeared after the correction for age and sex. In patients with ischemic stroke, microbleeds were associated with chronic hypertension in some studies, but others did not confirm this association [25].

Table 5 Relation between hypertension and the presence of microbleeds in patients with recurrent stroke

\begin{tabular}{|c|c|c|c|c|c|c|c|}
\hline & & \multicolumn{4}{|c|}{ Microbleeds } & \multirow{3}{*}{$\begin{array}{l}\text { Chi- } \\
\text { square } \\
\text { test }\end{array}$} & \multirow{3}{*}{$\begin{array}{l}P \\
\text { value }\end{array}$} \\
\hline & & \multicolumn{2}{|c|}{ Positive } & \multicolumn{2}{|c|}{ Negative } & & \\
\hline & & $N$ & $\%$ & $N$ & $\%$ & & \\
\hline \multirow[t]{2}{*}{ HTN } & Negative & 18 & 25.7 & 66 & 46.5 & 4.23 & 0.04 \\
\hline & Positive & 52 & 74.3 & 76 & 53.5 & & \\
\hline
\end{tabular}


Table 6 Relation between dyslipidemia and the presence of microbleeds

\begin{tabular}{llllll}
\hline & & \multicolumn{2}{l}{ Microbleeds.gr } & Total \\
\cline { 3 - 4 } & & & Negative & Positive & \\
\hline Hypercholesterolemia & - & Count & 44 & 84 & 128 \\
& & $\%$ & $16.7 \%$ & $76.4 \%$ & $34.2 \%$ \\
& + & Count & 220 & 26 & 246 \\
Total & $\%$ & $83.3 \%$ & $23.6 \%$ & $65.8 \%$ \\
& & Count & 264 & 110 & 374 \\
Chi-square tests & & $100.0 \%$ & $100.0 \%$ & $100.0 \%$ \\
& & & & \\
Pearson chi-square & & & & & \\
\hline
\end{tabular}

In the present study, CMBs were found to occur more frequently in deep brain areas in hypertensive patients. Several pathologic studies have observed that hypertensive angiopathy is predominantly noted in deep or infratentorial brain areas, while amyloid angiopathy is commonly situated in cerebral lobar regions [25]. Furthermore, other population-based observational studies have shown that hypertension or elevated blood pressure [26, 27] was associated with deep/infratentorial CMBs. These findings are in line with ours.

Intriguingly, a study by Lee et al. [28] investigating microbleeds in 129 hypertensive patients noted microbleeds to occur more frequently in the cortico-subcortical region.

The Rotterdam Scan Study has showed significant association of very low serum cholesterol levels $(<4.42 \mathrm{mmol} /$ $\mathrm{L}$ versus higher values) with the presence of strictly lobar microbleeds [27], whereas Yubi et al. [29] noted that lower total cholesterol levels were associated with the presence of deep/infratentorial CMBs in the Japanese elderly. In contrast, in our study, we found a significant association of hypercholesterolemia and the presence of microbleeds. The exact reason for the inconsistency between Japanese and Western studies and our study is unknown but may be due to dissimilarity in the genetic backgrounds, the age distributions, and lifestyles [26].

On the other hand, our study findings are in line with $\mathrm{Ni} \mathrm{R}$ et al. [30] who reported an association of multiple

Table 7 Relation between stroke subtype and the presence of microbleeds

\begin{tabular}{|c|c|c|c|c|c|c|c|}
\hline & & \multicolumn{4}{|c|}{ Microbleeds } & \multirow[t]{3}{*}{$x^{2}$} & \multirow{3}{*}{$\begin{array}{l}P \\
\text { value }\end{array}$} \\
\hline & & \multicolumn{2}{|c|}{ Positive } & \multicolumn{2}{|c|}{ Negative } & & \\
\hline & & $\bar{N}$ & $\%$ & $\bar{N}$ & $\%$ & & \\
\hline \multirow[t]{3}{*}{ Stroke subtype } & Atherothrombotic & 68 & 61.8 & 168 & 63.6 & 1.48 & 0.48 \\
\hline & Lacunar & 32 & 29.1 & 84 & 31.8 & & \\
\hline & Embolic & 10 & 9.1 & 12 & 4.5 & & \\
\hline
\end{tabular}

Table 8 Relation between hypertension and site of microbleeds

\begin{tabular}{|c|c|c|c|c|c|c|c|c|c|}
\hline & & \multicolumn{6}{|c|}{ Site of microbleeds } & \multirow{3}{*}{$\begin{array}{l}\text { Chi- } \\
\text { square } \\
\text { test }\end{array}$} & \multirow{3}{*}{$\begin{array}{l}P \\
\text { value }\end{array}$} \\
\hline & & \multicolumn{2}{|c|}{ Lobar } & \multicolumn{2}{|c|}{ Deep } & \multicolumn{2}{|c|}{ Mixed } & & \\
\hline & & $N$ & $\%$ & $N$ & $\%$ & $N$ & $\%$ & & \\
\hline \multirow[t]{2}{*}{ Hypertension } & Negative & 38 & 65.5 & 0 & 0.0 & 0 & 0.0 & \multirow{2}{*}{$\begin{array}{l}28.77 \\
F E\end{array}$} & \multirow[t]{2}{*}{$<0.001$} \\
\hline & Positive & 20 & 34.5 & 40 & 100.0 & 14 & 100.0 & & \\
\hline
\end{tabular}

CMBs with white matter hyperintensities (WMH), dyslipidemia, hyperhomocysteine, and uric acid.

$50.3 \%$ of our patients were diabetics. However, no significant associations have been found between CMBs and diabetes in our study participants. Association between CMBs and diabetes has been inconsistent across published reports [31].

In ischemic stroke, CMBs are more commonly reported in patients with small vessel disease ischemic stroke than in individuals having large vessel stroke (atherothromboembolic or cardioembolic) [32]. Kato et al. [19] reported a greater prevalence of CMBs in subjects with lacunar infarct (62\%) than those with cardioembolic infarct (30\%) and atherothrombotic infarct (21\%) in a study which included 213 patients with ischemic stroke. However, another study from Japan noted that CMBs were associated with atherothrombotic $(5 / 22,23 \%)$ and lacunar (7/31, $23 \%)$ but not in cardioembolic stroke $(0 / 13,0 \%)$ [17].

In our study, we did not find a significant association between the presence of CMBs and stroke subtype.

Our study revealed an association between the number of CMBs and the severity of white matter lesions as a higher number of $\mathrm{CMBs}$ related to more severe white matter lesions. A relationship between CMBs and severity of white matter hyperintensities, or leukoaraiosis, has

Table 9 Correlation between number of CMBs and severity of white matter lesions

\begin{tabular}{|c|c|c|c|c|c|c|c|}
\hline & & & \multicolumn{4}{|c|}{ Microbleeds' grade } & \multirow[t]{2}{*}{ Total } \\
\hline & & & 0 & 1 & 2 & 3 & \\
\hline \multirow[t]{8}{*}{ Fazekas score } & 0 & Count & 46 & 8 & 0 & 0 & 54 \\
\hline & & $\%$ & $17.4 \%$ & $10.3 \%$ & $0.0 \%$ & $0.0 \%$ & $14.4 \%$ \\
\hline & 1 & Count & 88 & 26 & 2 & 0 & 116 \\
\hline & & $\%$ & $33.3 \%$ & $33.3 \%$ & $12.5 \%$ & $0.0 \%$ & $31.0 \%$ \\
\hline & 2 & Count & 86 & 36 & 6 & 4 & 132 \\
\hline & & $\%$ & $32.6 \%$ & $46.2 \%$ & $37.5 \%$ & $25.0 \%$ & $35.3 \%$ \\
\hline & 3 & Count & 44 & 8 & 8 & 12 & 72 \\
\hline & & $\%$ & $16.7 \%$ & $10.3 \%$ & $50.0 \%$ & $75.0 \%$ & $19.3 \%$ \\
\hline \multirow{2}{*}{\multicolumn{2}{|c|}{ Total }} & Count & 264 & 78 & 16 & 16 & 374 \\
\hline & & $\%$ & $100.0 \%$ & $100.0 \%$ & $100.0 \%$ & $100.0 \%$ & $100.0 \%$ \\
\hline \multicolumn{8}{|c|}{ Chi-square tests } \\
\hline & & \multicolumn{2}{|c|}{ Value } & \multicolumn{3}{|l|}{$P$} & \\
\hline \multicolumn{2}{|c|}{ Pearson chi-square } & \multicolumn{2}{|c|}{28.031} & \multicolumn{3}{|l|}{$<0.001$} & \\
\hline
\end{tabular}


Table 10 Relation between the use of antithrombotic and the presence of microbleeds

\begin{tabular}{|c|c|c|c|c|c|c|c|}
\hline & & Micr & obleec & & & & $P$ value \\
\hline & & Posit & tive & $\mathrm{Neg}$ & ative & $\begin{array}{l}\text { square } \\
\text { test }\end{array}$ & \\
\hline & & $N$ & $\%$ & $N$ & $\%$ & & \\
\hline Antithrombotic & Negative & 10 & 9.1 & 252 & 95.5 & 138.3 & $<0.001$ \\
\hline & Positive & 100 & 90.9 & 12 & 4.5 & & \\
\hline
\end{tabular}

been reported in ischemic and hemorrhagic stroke patients [33-35], Alzheimer's dementia [36-38], vascular dementia [33], and community-dwelling elderly [23, 39]. These findings indicate that the detection of microbleeds reflects advanced stage of microangiopathy in which the blood vessels are prone to bleeding.

The association of antithrombotic treatment and prevalence of CMBs is still debated as some studies reported the relationship but not in others [24]. In our study, we observed that microbleeds were more prevalent in the group of patients using antithrombotics.

As a part of self-criticism, our study is limited as we included patients from only one tertiary referral center that covers a limited geographical area in Egypt. Future work including a bigger sample from a greater geographic area or be expanded to a multi-government analysis is encouraged.

\section{Conclusion}

The present study is the first observational study to explore the prevalence of CMBs and associated risk factors in Egyptian elderly with acute ischemic stroke.

In our study, we found that the prevalence of microbleeds is $29.4 \%$ (110/374 patients) in the elderly population of patients suffering from ischemic stroke. Age, hypercholesterolemia, and use of antithrombotics emerged as the most important associated risk factors for the presence of CMBs. On MRI, there was a significant association between the number of CMBs and severity of white matter lesions as a higher number of CMBs related to more severe white matter lesions.

Further prospective studies are required to define the risk factors for the development of CMBs and to set strategies for prevention of $\mathrm{CMBs}$ and consequent neurologic disorders including symptomatic stroke and dementia.

\section{Abbreviations}

CAA: Cerebral amyloid angiopathy; CMB: Cerebral microbleeds; GRE: Gradient echo; HV: Hypertensive vasculopathy; MRA: Magnetic resonance angiography; MRI: Magnetic resonance imaging

\section{Acknowledgements}

Not applicable

\section{Authors' contributions}

Al suggested and developed the research idea, shared in reviewing the literature and data analysis, and wrote the manuscript. YI contributed to the data collection and analysis and manuscript editing. ED contributed to the data collection and analysis and prepared the figures and tables. NK contributed to the data collection and analysis and reviewing the literature. All authors read and approved the final manuscript.

Funding

Not applicable

\section{Availability of data and materials}

The datasets used and/or analyzed during the current study are available from the corresponding author on reasonable request.

\section{Ethics approval and consent to participate}

The local ethics committee of Ain Shams University ruled that no formal ethics approval was required in this retrospective study. However, non-formal IRB approval was obtained.

\section{Consent for publication}

Not applicable

\section{Competing interests}

The authors declare that they have no competing interests.

\section{Author details}

${ }^{1}$ Geriatric Department, Faculty of Medicine, Ain Shams University, Cairo, Egypt. ${ }^{2}$ Radiology Department, Faculty of Medicine, Ain Shams University, Abbaseya Square, Cairo 11566, Egypt.

Received: 19 July 2019 Accepted: 19 August 2019

Published online: 02 October 2019

\section{References}

1. Greenberg SM, Vernooij MW, Cordonnier C, Viswanathan A, Al-Shahi Salman R, Warach S et al (2009) Cerebral microbleeds: a guide to detection and interpretation. Lancet Neurol 8:165-174

2. Offenbacher H, Fazekas F, Schmidt R, Koch M, Fazekas G, Kapeller P (1996) MR of cerebral abnormalities concomitant with primary intracerebral hematomas. Am J Neuroradiol 17:573-578

3. Tanaka A, Ueno Y, Nakayama Y, Takano K, Takebayashi S (1999) Small chronic hemorrhages and ischemic lesions in association with spontaneous intracerebral hematomas. Stroke 30:1637-1642

4. Fazekas F, Kleinert R, Roob G, Kleinert G, Kapeller P, Schmidt R, Hartung HP (1999) Histopathologic analysis of foci of signal loss on gradient-echo T2*weighted MR images in patients with spontaneous intracerebral hemorrhage: evidence of microangiopathy-related microbleeds. Am J Neuroradiol 20:637-642

5. Koennecke HC (2006) Cerebral microbleeds on MRI: prevalence, associations, and potential clinical implications. Neurology 66:165-171

6. Nishikawa T, Ueba T, Kajiwara M, Fujisawa I, Miyamatsu N, Yamashita K (2009) Cerebral microbleeds predict first-ever symptomatic cerebrovascular events. Clin Neurol Neurosurg 111:825-810

7. Werring DJ, Frazer DW, Coward L, Losseff NA, Watt H, Cipolotti L et al (2004) Cognitive dysfunction in patients with cerebral microbleeds on T2weighted gradient-echo MRI. Brain 127:2265-2275

8. Jeerakathil T, Wolf PA, Beiser A, Hald JK, Au R, Kase CS et al (2004) Cerebral microbleeds: prevalence and associations with cardiovascular risk factors in the Framingham Study. Stroke 35:1831-1835

9. Kinoshita T, Okudera T, Tamura H, Ogawa T, Hatazawa J (2000) Assessment of lacunar hemorrhage associated with hypertensive stroke by echo-planar gradient-echo T2*-weighted MRI. Stroke 31:1646-1650

10. Tsushima Y, Aoki J, Endo K (2003) Brain microhemorrhages detected on T2*weighted gradient-echo MR images. Am J Neuroradiol 24:88-96

11. Lee SH, Kwon SJ, Kim KS, Yoon BW, Roh JK (2004) Cerebral microbleeds in patients with hypertensive stroke. Topographical distribution in the supratentorial area. J Neurol 251:1183-1189

12. Lee SH, Kwon SJ, Kim KS, Yoon BW, Roh JK (2004) Topographical distribution of pontocerebellar microbleeds. Am J Neuroradiol 25:1337-1341

13. Imaizumi T, Horita Y, Chiba M, Hashimoto Y, Honma T, Niwa J (2004) Dotlike hemosiderin spots on gradient echo $\mathrm{T}^{*}$-weighted magnetic resonance imaging are associated with past history of small vessel disease in patients with intracerebral hemorrhage. J Neuroimaging 14:251-257 
14. (1990) Special Report from the National Institute of Neurological Disorders and Stroke. Classification of cerebrovascular diseases III. Stroke 21:637-676

15. Lee SH, Bae HJ, Yoon BW, Kim H, Kim DE, Roh JK (2002) Low concentration of serum total cholesterol is associated with multifocal signal loss lesions on gradient-echo magnetic resonance imaging: analysis of risk factors for multifocal signal loss lesions. Stroke 33:2845-2849

16. Fazekas F, Chawluk JB, Alavi A, Hurtig HI, Zimmerman RA (1987) MR signal abnormalities at 1.5 T in Alzheimer's dementia and normal aging. AJR Am J Roentgenol 149:351-356

17. Naka H, Nomura E, Wakabayashi S, Kajikawa H, Kohriyama T, Mimori Y, Nakamura S, Matsumoto M (2004) Frequency of asymptomatic microbleeds on $2^{*}$-weighted MR images of patients with recurrent stroke: association with combination of stroke subtypes and leukoaraiosis. AJNR Am J Neuroradiol. 25:714-719

18. Lee SH, Bae HJ, Kwon SJ, Kim H, Kim YH, Yoon BW, Roh JK (2004) Cerebral microbleeds are regionally associated with intracerebral hemorrhage. Neurology. 62:72-76

19. Kato H, Izumiyama M, Izumiyama K, Takahashi A, Itoyama Y (2002) Silent cerebral microbleeds on T2*-weighted MRI: correlation with stroke subtype, stroke recurrence, and leukoaraiosis. Stroke. 33:1536-1540

20. Cordonnier C, van der Flier WM, Sluimer JD, Leys D, Barkhof F, Scheltens P (2006) Prevalence and severity of microbleeds in a memory clinic setting. Neurology. 66:1356-1360

21. Tsushima Y, Tanizaki Y, Aoki J, Endo K (2002) MR detection of microhemorrhages in neurologically healthy adults. Neuroradiology. 44:31-36

22. Igase M, Tabara Y, Igase K, Nagai T, Ochi N, Kido T et al (2009) Asymptomatic cerebral microbleeds seen in healthy subjects have a strong association with asymptomatic lacunar infarction. Circ J. 73:530-533

23. Poels MM, Vernooij MW, Ikram MA, Hofman A, Krestin GP, van der Lugt A et al (2010) Prevalence and risk factors of cerebral microbleeds: an update of the Rotterdam Scan Study. Stroke. 41:S103-S106

24. Tang WK, Chen YK, Lu J, Ahuja AT, Chu WC, Mok VC et al (2011) Cerebral microbleeds and quality of life in acute ischemic stroke. Neurol Sci. 32:449-454

25. Cordonnier C, Al-Shahi Salman R, Wardlaw J (2007) Spontaneous brain microbleeds: systematic review, subgroup analyses and standards for study design and reporting. Brain 130:1988-2003

26. Romero JR, Preis SR, Beiser A et al (2014) Risk factors, stroke prevention treatments, and prevalence of cerebral microbleeds in the Framingham Heart Study. Stroke 45:1492-1494

27. Vernooij MW, van der Lugt A, Ikram MA et al (2008) Prevalence and risk factors of cerebral microbleeds: the Rotterdam Scan Study. Neurology 70: 1208-1214

28. Lee SH, Bae HJ, Ko SB, Kim H, Yoon BW, Roh JK (2004) Comparative analysis of the spatial distribution and severity of cerebral microbleeds and old lacunes. J Neurol Neurosurg Psychiatry 75:423-427

29. Yubi T, Hata J, Ohara T, Mukai N, Hirakawa Y, Yoshida D et al (2018) Prevalence of and risk factors for cerebral microbleeds in a general Japanese elderly community. Neurol Clin Pract 8(3):223-231

30. Ni R, Chu L, Xu D, Li Y, Zhang Y, You M, Zhu Y, Ouyang F, Zhang J, Cai G, Lin X, Yang Z, Gao Z (2018) Risk factors of cerebral microbleeds in young and middle-aged patients with hypertension. Neurol Res 40(5):413-418

31. Kim BJ, Lee SH, Kang BS, Yoon BW, Roh JK (2008) Diabetes increases large artery diseases, but not small artery diseases in the brain. J Neurol 255 1176-1181

32. Ovbiagele B, Saver JL, Sanossian N, Salamon N, Villablanca P, Alger JR et al (2006) Predictors of cerebral microbleeds in acute ischemic stroke and TIA patients. Cerebrovasc Dis 22:378-383

33. Hanyu H, Tanaka Y, Shimizu S, Takasaki M, Fujita H, Kaneko N et al (2003) Cerebral microbleeds in Binswanger's disease: a gradient-echo $\mathrm{T} 2^{*}$-weighted magnetic resonance imaging study. Neurosci Lett. 340:213-216

34. Lee S-H, Lee S-T, Kim BJ, Park H-K, Kim C-K, Jung K-H et al (2011) Dynamic temporal change of cerebral microbleeds: long-term follow-up MRI study. PLoS One 6(10):e25930

35. Alemany M, Stenborg A, Terent A, Sonninen P, Raininko R (2006) Coexistence of microhemorrhages and acute spontaneous brain hemorrhage: correlation with signs of microangiopathy and clinical data. Radiology 238:240-710

36. Pettersen JA, Sathiyamoorthy G, Gao F-Q, Szilagyi G, Nadkarni NK, St George-Hyslop P et al (2008) Microbleed topography, leukoaraiosis, and cognition in probable Alzheimer disease from the Sunnybrook dementia study. Arch Neurol 65:790
37. Nakata-Kudo Y, Mizuno T, Yamada K, Shiga K, Yoshikawa K, Mori S et al (2006) Microbleeds in Alzheimer disease are more related to cerebral amyloid angiopathy than cerebrovascular disease. Dement Geriatr Cogn Disord 22:8

38. Hanyu H, Tanaka Y, Shimizu S, Takasaki M, Abe K (2003) Cerebral microbleeds in Alzheimer's disease. J Neurol 250

39. Takashima Y, Mori T, Hashimoto M, Kinukawa N, Uchino A, Yuzuriha T et al (2011) Clinical correlating factors and cognitive function in communitydwelling healthy subjects with cerebral microbleeds. J Stroke Cerebrovasc Dis 20:105

\section{Publisher's Note}

Springer Nature remains neutral with regard to jurisdictional claims in published maps and institutional affiliations.

\section{Submit your manuscript to a SpringerOpen ${ }^{\circ}$ journal and benefit from:}

- Convenient online submission

- Rigorous peer review

- Open access: articles freely available online

- High visibility within the field

- Retaining the copyright to your article

Submit your next manuscript at $\boldsymbol{\nabla}$ springeropen.com 